\title{
The IMPROVEDD VTE Risk Score: Incorporation of D-Dimer into the IMPROVE Score to Improve Venous Thromboembolism Risk Stratification
}

\author{
C. Michael Gibson ${ }^{1} \quad$ Alex C. Spyropoulos ${ }^{2} \quad$ Alexander T. Cohen ${ }^{3} \quad$ Russell D. Hull ${ }^{4}$ \\ Samuel Z. Goldhaber ${ }^{5}$ Roger D. Yusen ${ }^{6} \quad$ Adrian F. Hernandez $^{7} \quad$ Serge Korjian $^{1} \quad$ Yazan Daaboul $^{1}$ \\ Alex Gold ${ }^{8}$ Robert A. Harrington ${ }^{9}$ Gerald $\mathrm{Chi}^{1}$
}

${ }^{1}$ Cardiovascular Division, Department of Medicine, Beth Israel Deaconess Medical Center, Harvard Medical School, Boston, Massachusetts, United States

2 Department of Medicine, Anticoagulation and Clinical Thrombosis Services, Hofstra Northwell School of Medicine, Northwell Health System, Manhasset, New York, United States

3 Department of Haematological Medicine, Guy's and St Thomas'

Hospitals, King's College, London, United Kingdom

${ }^{4}$ Division of Cardiology, Faculty of Medicine, University of Calgary, Alberta, Canada

${ }^{5}$ Cardiovascular Division, Brigham and Women's Hospital, Harvard

Medical School, Boston, Massachusetts, United States

${ }^{6}$ Divisions of Pulmonary and Critical Care Medicine and General Medical Sciences, Washington University School of Medicine,

St. Louis, Missouri, United States

${ }^{7}$ Department of Medicine, Duke University and Duke Clinical

Research Institute, Durham, North Carolina, United States

8 Portola Pharmaceuticals, Inc., South San Francisco,

California, United States

${ }^{9}$ Division of Cardiovascular Medicine, Department of Medicine, Stanford University, Stanford, California, United States

\begin{abstract}
Address for correspondence Gerald Chi, MD, PERFUSE Study Group, Cardiovascular Division, Department of Medicine, Beth Israel Deaconess Medical Center, Harvard Medical School, 330 Brookline Avenue, Suite OV-540, Boston, MA 02215, United States (e-mail: geraldcchi@gmail.com).
\end{abstract}

TH Open 2017;1:e56-e65.

\author{
Abstract \\ Keywords \\ - venous \\ thromboembolism \\ - D-dimer \\ - risk assessment \\ model \\ - thromboprophylaxis
}

Background The IMPROVE score is a validated venous thromboembolism (VTE) assessment tool to risk stratify hospitalized, medically ill patients based on clinical variables. It was hypothesized that addition of D-dimer measurement to derive a new IMPROVEDD score would improve identification of at risk of VTE.

Methods The association of the IMPROVE score and D-dimer $\geq 2 \times$ the upper limit of normal (ULN) with the risk of symptomatic deep vein thrombosis, nonfatal pulmonary embolism, or VTE-related death was evaluated in 7,441 hospitalized, medically ill patients randomized in the APEX trial. Based on the Cox regression analysis, the IMPROVEDD score was derived by adding two points to the IMPROVE score if the D-dimer was $\geq 2 \times$ ULN.

Results Baseline D-dimer was independently associated with symptomatic VTE through 77 days (adjusted HR: 2.22 [95\% Cl: 1.38-1.58], $p=0.001$ ). Incorporation of D-dimer into the IMPROVE score improved VTE risk discrimination ( $\triangle \mathrm{AUC}$ : 0.06 [95\% Cl: $0.02-0.09], p=0.0006$ ) and reclassification (continuous NRI: 0.34 [95\% Cl: $0.17-$ 0.51 ], $p=0.001$; categorical NRI: 0.13 [95\% Cl: 0.03-0.23], $p=0.0159$ ). Patients with an IMPROVEDD score of $\geq 2$ had a greater VTE risk compared with those with an IMPROVEDD score of 0 to 1 (HR: 2.73 [95\% Cl: 1.52-4.90], $p=0.0007$ ).
DOI https://doi.org/ $10.1055 / \mathrm{s}-0037-1603929$. ISSN $2512-9465$. (c) 2017 Georg Thieme Verlag KG Stuttgart · New York
License terms

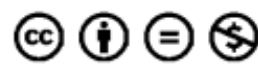


Conclusion Incorporation of D-dimer into the IMPROVE VTE risk assessment model further improves risk stratification in hospitalized, medically ill patients who received thromboprophylaxis. An IMPROVEDD score of $\geq 2$ identifies hospitalized, medically ill patients with a heightened risk for VTE through 77 days.

\section{Introduction}

Venous thromboembolism (VTE) is a major contributor to the global disease burden with an estimated incidence of 3.0 to 3.3 cases per 100 hospitalizations per year. ${ }^{1}$ Hospitalized, medically ill patients represent a population with heterogeneous predisposition to VTE for which risk assessment is recommended prior to thromboprophylaxis. ${ }^{2-4}$ However, existing risk assessment models (RAMs) may not adequately identify at-risk subsets, and risk stratification remains an ongoing challenge and imprecise science. ${ }^{5,6} \mathrm{D}$-dimer, a biomarker for fibrinolysis, has been associated with heightened VTE risk among patients hospitalized for an acute medical illness. ${ }^{7-9}$ The International Medical Prevention Registry on Venous Thromboembolism (IMPROVE) VTE RAM has undergone extensive external validation in the medically ill population. $6,10,11$ In this article, D-dimer was incorporated into the IMPROVE VTE RAM to derive the IMPROVEDD VTE risk score. ${ }^{12}$ The model-based performance was tested in a cohort of hospitalized medical patients receiving primary pharmacologic prophylaxis. It was hypothesized that incorporation of the biomarker D-dimer would provide incremental prognostic value to the IMPROVE RAM in identifying patients at risk of developing symptomatic deep vein thrombosis, nonfatal pulmonary embolism, and VTE-related death.

\section{Methods}

\section{Study Design}

The Acute Medically Ill VTE (Venous Thromboembolism) Prevention with Extended Duration Betrixaban Trial (APEX; ClinicalTrials.gov identifier: NCT01583218) was a randomized, double-blind, multinational clinical trial that compared extended-duration betrixaban ( $80 \mathrm{mg}$ once daily for 35-42 days) to standard-duration enoxaparin (40 $\mathrm{mg}$ once daily for $10 \pm 4$ days) among hospitalized medical patients. ${ }^{9,13}$ Four principal enrollment criteria were as follows: (1) hospitalization for acute medical illness, including heart failure, respiratory failure, infection, ischemic stroke, or rheumatic disorder; (2) age $\geq 75$ years, age 60 to 74 years with D-dimer $\geq 2 \times$ the upper limit of normal (ULN), or age 40 to 59 years with D-dimer $\geq 2 \times$ ULN and history of VTE or cancer; (3) anticipated severe immobilization for $\geq 24$ hours followed by moderate or severe immobilization for 3 or more days; and (4) anticipated hospitalization for 3 or more days. Serum samples for D-dimer were obtained at the time of screening and sent to the central laboratory for analysis using the quantitative STA Liatest D-Di immunoturbidimetric assay (Diagnostica Stago, Asnières-sur-Seine, France). Endpoints were assessed at 42 and 77 days after randomiza- tion to approximate the 90-day endpoint from the original IMPROVE VTE RAM. All VTE events were adjudicated by an independent clinical events committee blinded to thromboprophylaxis allocation based on the documentation from the case report form, the narratives prepared by the study sites, and any other available supporting source documentation. The process of events adjudication occurred in two phases (Phase I and Phase II). Phase I review was conducted by two independent physicians. If the Phase I reviewers agreed in the adjudication of the event, the process was complete. If the Phase I reviewers did not agree, the event was submitted for adjudication by Phase II physician committee. In the Phase II meeting, each case was decided by majority rule of the Phase II reviewers. The enrollment period was from March 2012 to October 2015 and the follow-up of the last patient was completed in January 2016.

\section{Statistical Analysis}

All randomized patients fulfilling the enrollment criteria were included in the analyses. Baseline characteristics among patients with and without events were compared using the $x^{2}$ test for categorical variables and the one-way ANOVA or Kruskal-Wallis test for continuous variables, as appropriate. Cumulative incidence of symptomatic VTE from randomization to 42 and 77 days was estimated by the Kaplan-Meier method. To test the association between D-dimer and VTE-related events, univariate and multivariate regression analyses evaluated variables included in the IMPROVE associative model (i.e., previous VTE, known thrombophilia, current lower-limb paralysis, current cancer, immobilized $\geq 7$ days, intensive care unit (ICU) or coronary care unit (CCU) stay, and age $>60$ years). An additional sensitivity analysis that considered the confounding effect of thromboprophylaxis on this association was performed. To determine the appropriate weight for D-dimer, the risk estimate of D-dimer relative to the per point increase in the IMPROVE score was calculated from the adjusted Cox proportional hazards model. Consequently, the IMPROVEDD score was calculated by adding two points to the IMPROVE score if the D-dimer level was $\geq 2 \times$ ULN.

The model-based probability for the IMPROVE and IMPROVEDD score was estimated using logistic regression analysis. Metrics of model discrimination and reclassification were computed to assess the improvement in VTE predictability by the IMPROVEDD score, including area under the receiver-operating-characteristic curve (AUC), integrated discrimination improvement (IDI), and net reclassification improvement (NRI). ${ }^{14}$ Model calibration was assessed by comparing the observed and predicted risk for 
each IMPROVEDD score category. In addition, decision curve analysis was performed to compare the net benefit of the IMPROVE and IMPROVEDD score in VTE prediction. ${ }^{15} \mathrm{~A}$ cutoff for the IMPROVEDD score corresponding to an event rate of $\geq 1 \%$, as recommended for warranting pharmacologic prophylaxis by the American College of Chest Physicians (ACCP) guidelines, was used to dichotomize patients as atrisk versus low-risk category. Accordingly, the risk for symptomatic VTE was compared between the at-risk warranting prophylaxis ( $\geq 2$ points) and low-risk (0-1 points) categories. Analyses were performed independently by an academic research organization, Percutaneous-Pharmacologic Endoluminal Revascularization for Unstable Syndromes Evaluation (PERFUSE) Study Group, using SAS software version 9.4 (SAS Institute, Inc., Cary, North Carolina, United States).

\section{Results}

\section{Baseline Characteristics}

Patients who developed symptomatic VTE at 77 days were hospitalized longer and were more likely to have had a previous VTE, ICU or CCU stay, higher IMPROVE score, and D-dimer $\geq 2 \times$ ULN ( - Table 1). Age, sex, race, weight, height, body mass index, creatinine clearance, and acute medical condition were balanced between patients with events and without events.

\section{Risk Stratification by D-Dimer}

Baseline D-dimer levels were measured in 7,235 patients. The risk for symptomatic VTE was significantly higher among patients with D-dimer $\geq 2 \times$ ULN compared with $<2 \times$ ULN, with respective rates of 1.11 versus $0.57 \%$ at 42 days and 2.37 versus $1.00 \%$ at 77 days (HR: 2.26 [95\% CI: 1.41-3.64], $p=0.0008$; - Fig. 1). Of the seven risk factors identified in the IMPROVE RAM study, previous VTE and ICU or CCU stay were statistically associated with symptomatic VTE in the study population (-Table 2 ). Multivariate analysis confirmed that D-dimer was independently associated with symptomatic VTE at 42 days (adjusted HR: 2.28 [95\% CI: $1.35-3.85], p=0.0020$ ) and at 77 days (adjusted HR: 2.22 [95\% CI: $1.38-3.58$ ], $p=0.0010$ ). When thromboprophylaxis allocation was considered in the model, estimates for the VTE risk factors do not alter substantially (-Table S1, supplementary table available in the online version only).

\section{Derivation of the IMPROVEDD VTE Risk Score}

In the Cox proportional hazards model, symptomatic VTE risk was approximately 2.26 to 2.33 times greater among patients with D-dimer $\geq 2 \times$ ULN compared with $<2 \times$ ULN ( - Table 3). The risk was approximately 1.22 to 1.26 times greater for each point increase in the IMPROVE score. There was no significant interaction between D-dimer and the IMPROVE score in the model $(p=0.41$ at 42 days and $p=0.61$ at 77 days). Based on the relative size of the risk estimates, the IMPROVEDD VTE risk score was derived by adding two points to the IMPROVE score for patients with Ddimer $\geq 2 \times$ ULN ( - Table 4).

\section{Risk Discrimination and Reclassification by the IMPROVEDD Score}

Metrics of model discrimination and reclassification are summarized in - Tables $\mathbf{4}$ and $\mathbf{5}$. The AUC of the D-dimer, IMPROVE score, and IMPROVEDD score were 0.588, 0.560, and 0.621 at 42 days and $0.584,0.568$, and 0.625 at 77 days, respectively (-Fig. 2). Addition of D-dimer to the IMPROVE score significantly improved the risk discrimination and reclassification at 42 and 77 days.

The observed and predicted risk for each IMPROVEDD score category is provided in -Table 6 . The rates were generally comparable in the two categories that comprise the majority of patients: IMPROVEDD scores of 1 (28.4\%) and 3 (48.7\%). Calibration of the IMPROVEDD score was suboptimal in the other categories: overestimation was noted in the score of 0 and $\geq 5$, whereas underestimation was noted in the scores of 2 and 4 . Decision curves of the IMPROVE and IMPROVEDD scores in VTE prediction at 42 and 77 days were shown in - Figs. S1 and S2 (supplementary figures available in the online version only). With the VTE threshold of $1 \%$ that corresponds to the cutoff warranting pharmacologic prophylaxis, IMPROVE score is associated with minimal net benefit ( 0.002 at both 42 and 77 days) against the "treat all" strategy, whereas the use of IMPROVEDD score would avoid undue thromboprophylaxis in 15 and 11 per 100 patients, respectively.

Identifying At-Risk Patients by the IMPROVEDD Score The American College of Chest Physicians ${ }^{2}$ selected a cutoff corresponding to an event rate of $\geq 1 \%$ to dichotomize individuals as at-risk and in need of prophylaxis versus low-risk. Consequently, patients with an IMPROVEDD score of $\geq 2$ were deemed as at-risk, whereas those with a score of 0 to 1 were deemed to be at low-risk ( - Table 7 ). Compared with low-risk patients, at-risk patients had a higher rate of symptomatic VTE at 42 and 77 days. The Kaplan-Meier rates of symptomatic VTE were 1.11 versus $0.39 \%$ at 42 days and 2.22 versus $0.91 \%$ at 77 days (HR: 2.73 [95\% CI: $1.52-4.90$ ], $p=0.0007$; - Fig. 3).

\section{Discussion}

Incorporation of the quantitative D-dimer level, which increases as overall hypercoagulability increases, provides incremental prognostic value to the IMPROVE VTE RAM at 42 and 77 days. Incorporating D-dimer into the IMPROVE VTE risk score significantly improves VTE risk discrimination and reclassification. An IMPROVEDD score of $\geq 2$ identified a subset of hospitalized, medically ill patients at a sustained, heightened symptomatic VTE risk through 77 days.

VTE risk assessment for hospitalized patients has been associated with reduced morbidity, mortality, and incidence of hospital-acquired thrombosis. ${ }^{16-18}$ To identify the at-risk population and to guide appropriate thromboprophylaxis among hospitalized patients, several RAMs have been developed using clinical parameters. ${ }^{12,19-21}$ Research efforts have focused on exploring biomarkers associated with VTE in various populations. D-dimer has been considered as one 
Table 1 Patient characteristics in the study population with and without symptomatic VTE

\begin{tabular}{|c|c|c|}
\hline Characteristic & $\begin{array}{l}\text { With symptomatic } \\
\text { VTE }(N=104)\end{array}$ & $\begin{array}{l}\text { Without symptomatic } \\
\text { VTE }(N=7,337)\end{array}$ \\
\hline Age, mean (SD)-y & $77.0(9.0)$ & $76.4(8.4)$ \\
\hline Male sex, $n(\%)$ & $43(41.3)$ & $3,349(45.6)$ \\
\hline \multicolumn{3}{|l|}{ Race, $n(\%)$} \\
\hline White & $94(90.4)$ & $6,868(93.6)$ \\
\hline Black/African American & $3(2.9)$ & $137(1.9)$ \\
\hline Asian & $0(0.0)$ & $16(0.2)$ \\
\hline Others & $7(6.7)$ & $316(4.3)$ \\
\hline Weight, mean (SD)-kg & $81.8(19.8)$ & $80.3(19.3)$ \\
\hline Height, mean (SD)-cm & $166.4(8.4)$ & $165.3(9.1)$ \\
\hline Body mass index, mean $(S D)-k g / \mathrm{m}^{2}$ & $29.5(6.9)$ & $29.4(6.6)$ \\
\hline \multicolumn{3}{|l|}{ Creatinine clearance, $n(\%)$} \\
\hline$<30 \mathrm{~mL} / \mathrm{min}$ & $7(6.7)$ & $316(4.3)$ \\
\hline$\geq 30$ to $<60 \mathrm{~mL} / \mathrm{min}$ & $46(44.2)$ & $3,055(41.7)$ \\
\hline$\geq 60$ to $<90 \mathrm{~mL} / \mathrm{min}$ & $32(30.8)$ & $2,595(35.5)$ \\
\hline$\geq 90 \mathrm{~mL} / \mathrm{min}$ & $19(18.3)$ & $1,352(18.5)$ \\
\hline Duration of hospitalization, median $(\mathrm{Q} 1, \mathrm{Q} 3)^{\mathrm{a}}$ & $12.0(7.0,17.0)$ & $10.0(8.0,14.0)$ \\
\hline \multicolumn{3}{|l|}{ Acute medical condition, $n(\%)$} \\
\hline Heart failure & $34(32.7)$ & $3,304(45.0)$ \\
\hline Respiratory failure & $20(19.2)$ & $885(12.1)$ \\
\hline Infection & $33(31.7)$ & $2,103(28.7)$ \\
\hline Rheumatic disorder & $3(2.9)$ & $219(3.0)$ \\
\hline Ischemic stroke & $14(13.5)$ & $824(11.2)$ \\
\hline \multicolumn{3}{|l|}{ IMPROVE VTE risk factor, $n(\%)$} \\
\hline Previous VTE ${ }^{\mathrm{a}}$ & $17(16.3)$ & $581(7.9)$ \\
\hline Known thrombophilia ${ }^{b}$ & $0(0.0)$ & $8(0.1)$ \\
\hline Current lower-limb paralysis & $7(6.7)$ & $559(7.6)$ \\
\hline Current cancer & $3(2.9)$ & $284(3.9)$ \\
\hline Immobilized $\geq 7 \mathrm{~d}$ & $0(0.0)$ & $0(0.0)$ \\
\hline ICU or CCU stay ${ }^{a}$ & $21(20.2)$ & $682(9.3)$ \\
\hline Age $>60 y$ & $99(95.2)$ & 7,037 (95.9) \\
\hline \multicolumn{3}{|l|}{ IMPROVE score, $n(\%)^{\text {a }}$} \\
\hline 0 & $1(1.0)$ & $119(1.6)$ \\
\hline 1 & $63(60.6)$ & $5,322(72.5)$ \\
\hline 2 & $14(13.5)$ & $561(7.6)$ \\
\hline 3 & $8(7.7)$ & $777(10.6)$ \\
\hline 4 & $15(14.4)$ & $463(6.3)$ \\
\hline$\geq 5$ & $3(2.9)$ & $95(1.3)$ \\
\hline IMPROVE score, median $(\mathrm{Q} 1, \mathrm{Q} 3)^{\mathrm{a}}$ & $1.0(1.0,2.5)$ & $1.0(1.0,2.0)$ \\
\hline D-dimer $\geq 2 \times$ ULN, $n(\%)^{\mathrm{a}}$ & $75(77.3)$ & $4,315(60.5)$ \\
\hline
\end{tabular}

Abbreviations: CCU, coronary care unit; ICU, intensive care unit; ULN, upper limit of normal; VTE, venous thromboembolism.

${ }^{\mathrm{a}} \mathrm{p}<0.05$.

${ }^{\mathrm{b}}$ Defined as inherited or acquired disorder of hemostasis including antithrombin III deficiency, protein C deficiency, and protein S deficiency. 


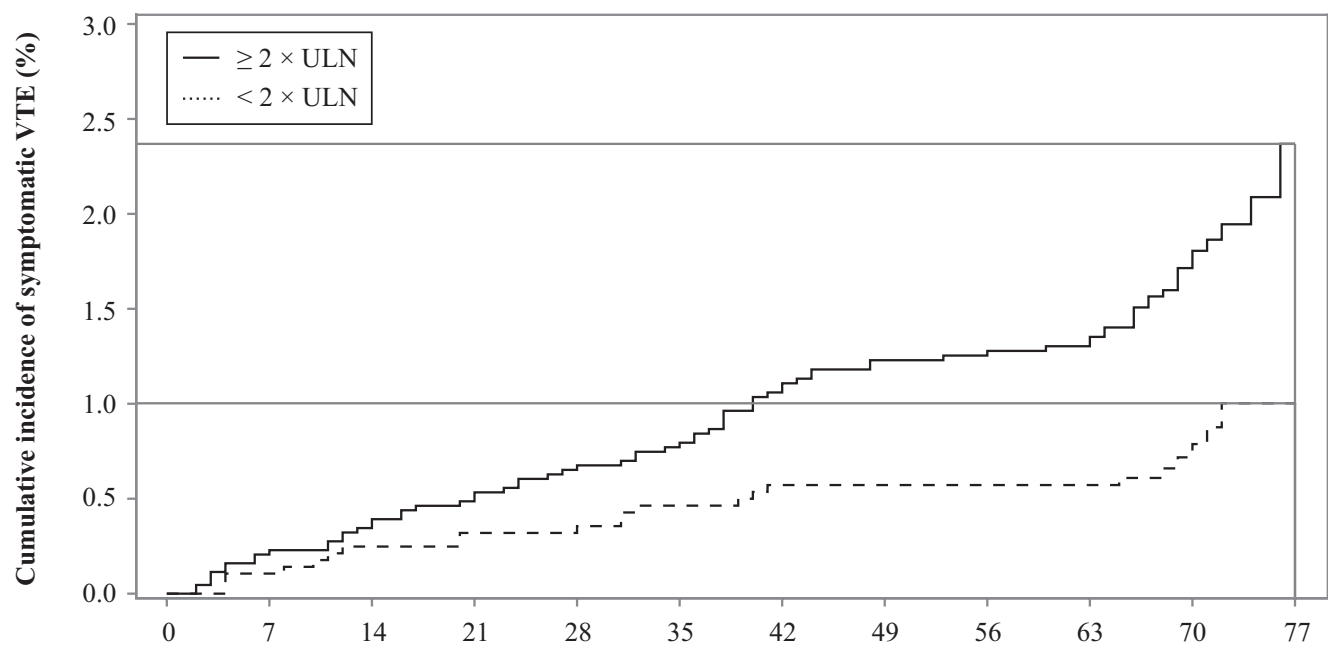

Time after randomization (days)

Fig. 1 Kaplan-Meier curves for symptomatic VTE stratified by D-dimer concentration.

Table 2 Univariable and multivariable regression analysis of VTE risk factors ${ }^{\mathrm{a}}$

\begin{tabular}{|c|c|c|c|c|c|}
\hline \multirow[t]{2}{*}{ Variable } & \multirow[t]{2}{*}{ Comparison } & \multicolumn{2}{|l|}{ Univariable model } & \multicolumn{2}{|l|}{ Multivariable model } \\
\hline & & $\mathrm{HR}(95 \% \mathrm{Cl})$ & $p$-Value & Adjusted HR (95\% Cl) & $p$-Value \\
\hline \multicolumn{6}{|l|}{ At $42 \mathrm{~d}$} \\
\hline D-dimer & $\geq 2 \times$ ULN vs. $<2 \times$ ULN & $2.33(1.38-3.94)$ & 0.0015 & $2.28(1.35-3.85)$ & 0.0020 \\
\hline \multicolumn{6}{|l|}{ IMPROVE VTE risk factor } \\
\hline Previous VTE & Yes vs. no & $2.31(1.32-4.02)$ & 0.0032 & $2.20(1.16-4.17)$ & 0.0155 \\
\hline Known thrombophilia & Yes vs. no & - & - & - & - \\
\hline $\begin{array}{l}\text { Current lower-limb } \\
\text { paralysis }\end{array}$ & Yes vs. no & $0.58(0.21-1.59)$ & 0.29 & $0.66(0.24-1.79)$ & 0.41 \\
\hline Current cancer & Yes vs. no & $0.58(0.14-2.35)$ & 0.44 & $0.63(0.16-2.57)$ & 0.52 \\
\hline Immobilization & $\geq 7$ d vs. $<7 d$ & - & - & - & - \\
\hline ICU or CCU stay & Yes vs. no & $2.60(1.55-4.37)$ & 0.0003 & $2.95(1.75-4.99)$ & $<0.0001$ \\
\hline Age & $>60$ y vs. $\leq 60$ y & $0.72(0.29-1.78)$ & 0.48 & $0.99(0.37-2.62)$ & 0.98 \\
\hline \multicolumn{6}{|l|}{ At $77 \mathrm{~d}$} \\
\hline D-dimer & $\geq 2 \times$ ULN vs. $<2 \times$ ULN & $2.26(1.41-3.64)$ & 0.0008 & $2.22(1.38-5.38)$ & 0.0010 \\
\hline \multicolumn{6}{|l|}{ IMPROVE VTE risk factor } \\
\hline Previous VTE & Yes vs. no & $2.21(1.32-3.72)$ & 0.0028 & $2.20(1.22-3.97)$ & 0.0084 \\
\hline Known thrombophilia & Yes vs. no & - & - & - & - \\
\hline $\begin{array}{l}\text { Current lower-limb } \\
\text { paralysis }\end{array}$ & Yes vs. no & $0.91(0.42-1.96)$ & 0.81 & $1.01(0.47-2.18)$ & 0.98 \\
\hline Current cancer & Yes vs. no & $0.75(0.24-2.36)$ & 0.62 & $0.82(0.26-2.59)$ & 0.73 \\
\hline Immobilization & $\geq 7$ vs. $<7 d$ & - & - & - & - \\
\hline ICU or CCU stay & Yes vs. no & $2.69(1.67-4.34)$ & $<0.0001$ & $2.98(1.84-4.84)$ & $<0.0001$ \\
\hline Age & $>60$ vs. $\leq 60 \mathrm{y}$ & $0.86(0.35-2.11)$ & 0.74 & $1.20(0.46-3.14)$ & 0.71 \\
\hline
\end{tabular}

Abbreviations: CCU, coronary care unit; HR, hazard ratio; ICU, intensive care unit; ULN, upper limit of normal; VTE, venous thromboembolism. ${ }^{\mathrm{a}} \mathrm{A}$ total of 206 patients with incomplete covariate information were dropped from the model. 
Table 3 Cox proportional hazards model for symptomatic VTE

\begin{tabular}{|l|l|l|l|}
\hline Variable & Comparison & HR (95\% CI) & $p$-Value \\
\hline At 42 d & $\geq 2 \times$ ULN vs. $<2 \times$ ULN & $2.33(1.38-3.94)$ & 0.0015 \\
\hline D-dimer & Per point increase & $1.22(1.03-1.45)$ & 0.0223 \\
\hline IMPROVE score & $\geq 2 \times$ ULN vs. $<2 \times$ ULN & $2.26(1.41-3.64)$ & 0.0008 \\
\hline At 77 d & Per point increase & $1.26(1.09-1.47)$ & 0.0026 \\
\hline D-dimer & & & \\
\hline IMPROVE score &
\end{tabular}

Abbreviations: HR, hazard ratio; ULN, upper limit of normal.

Table 4 Improvement in model performance by the IMPROVEDD VTE risk score

\begin{tabular}{|c|c|c|}
\hline Metric & Value & $p$-Value \\
\hline \multicolumn{3}{|l|}{ At $42 \mathrm{~d}$} \\
\hline$\triangle \mathrm{AUC}$ & $0.061(0.026-0.097)$ & 0.0008 \\
\hline \multicolumn{3}{|l|}{ IDI } \\
\hline Absolute & $0.0012(0.0005-0.0019)$ & 0.0004 \\
\hline Relative & 1.71 & \\
\hline \multicolumn{3}{|l|}{ NRI, continuous } \\
\hline Overall & $0.346(0.162-0.530)$ & 0.0018 \\
\hline Events correctly reclassified & $54 \%$ & $<0.0001$ \\
\hline Nonevents correctly reclassified & $-19 \%$ & $<0.0001$ \\
\hline \multicolumn{3}{|l|}{ NRI, categorical } \\
\hline Overall & $0.215(0.111-0.319)$ & $<0.0001$ \\
\hline Events correctly reclassified & $-6 \%$ & 0.25 \\
\hline Nonevents correctly reclassified & $28 \%$ & $<0.0001$ \\
\hline \multicolumn{3}{|l|}{ At $77 \mathrm{~d}$} \\
\hline$\triangle \mathrm{AUC}$ & $0.057(0.024-0.090)$ & 0.0006 \\
\hline \multicolumn{3}{|l|}{ IDI } \\
\hline Absolute & $0.0015(0.0007-0.0023)$ & 0.0002 \\
\hline Relative & 1.25 & \\
\hline \multicolumn{3}{|l|}{ NRI, continuous } \\
\hline Overall & $0.337(0.169-0.506)$ & 0.0010 \\
\hline Events correctly reclassified & $55 \%$ & $<0.0001$ \\
\hline Nonevents correctly reclassified & $-21 \%$ & $<0.0001$ \\
\hline \multicolumn{3}{|l|}{ NRI, categorical } \\
\hline Overall & $0.125(0.026-0.225)$ & 0.0159 \\
\hline Events correctly reclassified & $-11 \%$ & 0.0278 \\
\hline Nonevents correctly reclassified & $24 \%$ & $<0.0001$ \\
\hline
\end{tabular}

Abbreviations: $\triangle A U C$, improvement in the area under ROC curve; IDI, integrated discrimination improvement; NRI, net reclassification improvement.

of the most promising, well-validated, readily available markers for VTE prediction, particularly among cancer patients. $^{22} \mathrm{D}$-dimer has also been used in combination with gender and the location of VTE to predict recurrence after discontinuing anticoagulation. ${ }^{23}$ This is the first study to demonstrate the complementary nature of combining a biomarker such as D-dimer with clinical variables for the risk stratification of hospitalized, medically ill patients. Results from this study demonstrate that there is a spectrum of thromboembolic risk across the IMPROVEDD score categories, with a higher score indicating a greater VTE risk that persists beyond the course of hospitalization. At-risk 
Table 5 Reclassification by the IMPROVEDD VTE risk score ${ }^{a}$

\begin{tabular}{|c|c|c|c|c|}
\hline \multirow[t]{2}{*}{ Estimated risk by the IMPROVE score } & \multicolumn{3}{|c|}{ Estimated risk by the IMPROVEDD score } & \multirow[t]{2}{*}{ Total } \\
\hline & $<1 \%$ & $\geq 1 \%$ to $<2 \%$ & $\geq 2 \%$ & \\
\hline \multicolumn{5}{|l|}{ At $42 \mathrm{~d}$} \\
\hline \multicolumn{5}{|l|}{ Overall } \\
\hline$<1 \%$ & $117(100.0)$ & $0(0.0)$ & $0(0.0)$ & 117 \\
\hline$\geq 1 \%$ to $<2 \%$ & $2,263(32.2)$ & $4,461(63.5)$ & $301(4.3)$ & 7,025 \\
\hline$\geq 2 \%$ & $0(0.0)$ & $15(16.1)$ & $78(83.9)$ & 93 \\
\hline Total & 2,380 & 4,476 & 379 & 7,235 \\
\hline \multicolumn{5}{|l|}{ Events } \\
\hline$<1 \%$ & $1(0.0)$ & $0(0.0)$ & $0(0.0)$ & 1 \\
\hline$\geq 1 \%$ to $<2 \%$ & $12(15.2)$ & $60(75.9)$ & $7(8.9)$ & 79 \\
\hline$\geq 2 \%$ & $0(0.0)$ & $0(0.0)$ & $2(100.0)$ & 2 \\
\hline Total & 13 & 60 & 9 & 82 \\
\hline \multicolumn{5}{|l|}{ Nonevents } \\
\hline$<1 \%$ & $116(100.0)$ & $0(0.0)$ & $0(0.0)$ & 116 \\
\hline$\geq 1 \%$ to $<2 \%$ & $2,251(32.4)$ & $4,401(63.4)$ & $294(4.2)$ & 6,946 \\
\hline$\geq 2 \%$ & $0(0.0)$ & 15 (16.5) & $76(83.5)$ & 91 \\
\hline Total & 2,367 & 4,416 & 370 & 7,153 \\
\hline \multicolumn{5}{|l|}{ At $77 \mathrm{~d}$} \\
\hline \multicolumn{5}{|l|}{ Overall } \\
\hline$<1 \%$ & $48(41.0)$ & $69(59.0)$ & $0(0.0)$ & 117 \\
\hline$\geq 1 \%$ to $<2 \%$ & $2,053(31.3)$ & $4,077(62.1)$ & $431(6.6)$ & 6,561 \\
\hline$\geq 2 \%$ & $0(0.0)$ & $163(29.3)$ & $394(70.7)$ & 557 \\
\hline Total & 2,101 & 4,309 & 825 & 7,235 \\
\hline \multicolumn{5}{|l|}{ Events } \\
\hline$<1 \%$ & $0(0.0)$ & $1(100.0)$ & $0(0.0)$ & 1 \\
\hline$\geq 1 \%$ to $<2 \%$ & $13(16.3)$ & $61(76.3)$ & $6(7.5)$ & 80 \\
\hline$\geq 2 \%$ & $0(0.0)$ & $5(31.3)$ & $11(68.8)$ & 16 \\
\hline Total & 13 & 67 & 17 & 97 \\
\hline \multicolumn{5}{|l|}{ Nonevents } \\
\hline$<1 \%$ & $48(41.4)$ & 68 (58.6) & $0(0.0)$ & 116 \\
\hline$\geq 1 \%$ to $<2 \%$ & $2,040(31.5)$ & $4,016(62.0)$ & $425(6.6)$ & 6,481 \\
\hline$\geq 2 \%$ & $0(0.0)$ & $158(29.2)$ & $383(70.8)$ & 541 \\
\hline Total & 2,088 & 4,242 & 808 & 7,138 \\
\hline
\end{tabular}

aValues expressed as number of patients (row percentage).

patients, as identified by the IMPROVEDD score, may be appropriate candidates for extended thromboprophylaxis to minimize the risk of symptomatic VTE.

With the intent of maintaining generalizability from the IMPROVE derivation cohort, the weights for each VTE risk factor were unchanged, and two points were added to the original score for patients with D-dimer $\geq 2 \times U L N$. It is notable that adding D-dimer measurement to the IMPROVE score has been implemented in the enrollment criteria of an ongoing trial for preventing hospital-associated VTE (Medically Ill Patient Assessment of Rivaroxaban Versus Placebo in
Reducing Post-Discharge Venous Thrombo-Embolism Risk [MARINER]). ${ }^{24}$ In the MARINER study, eligible patients (i.e., "high-risk" patients) must have a total modified IMPROVE VTE risk score of $\geq 4$, or a risk score of 2 or 3 with a plasma Ddimer level of more than twice the ULN. The relative weight for D-dimer of $\geq 2 \times$ ULN is equivalent to two points when taken together with the IMPROVE VTE risk score and matches the rationale in this analysis. Furthermore, it supports the use of D-dimer measurement in conjunction with a standardized RAM for optimizing VTE risk assessment among acutely ill, hospitalized medical patients. However, although 

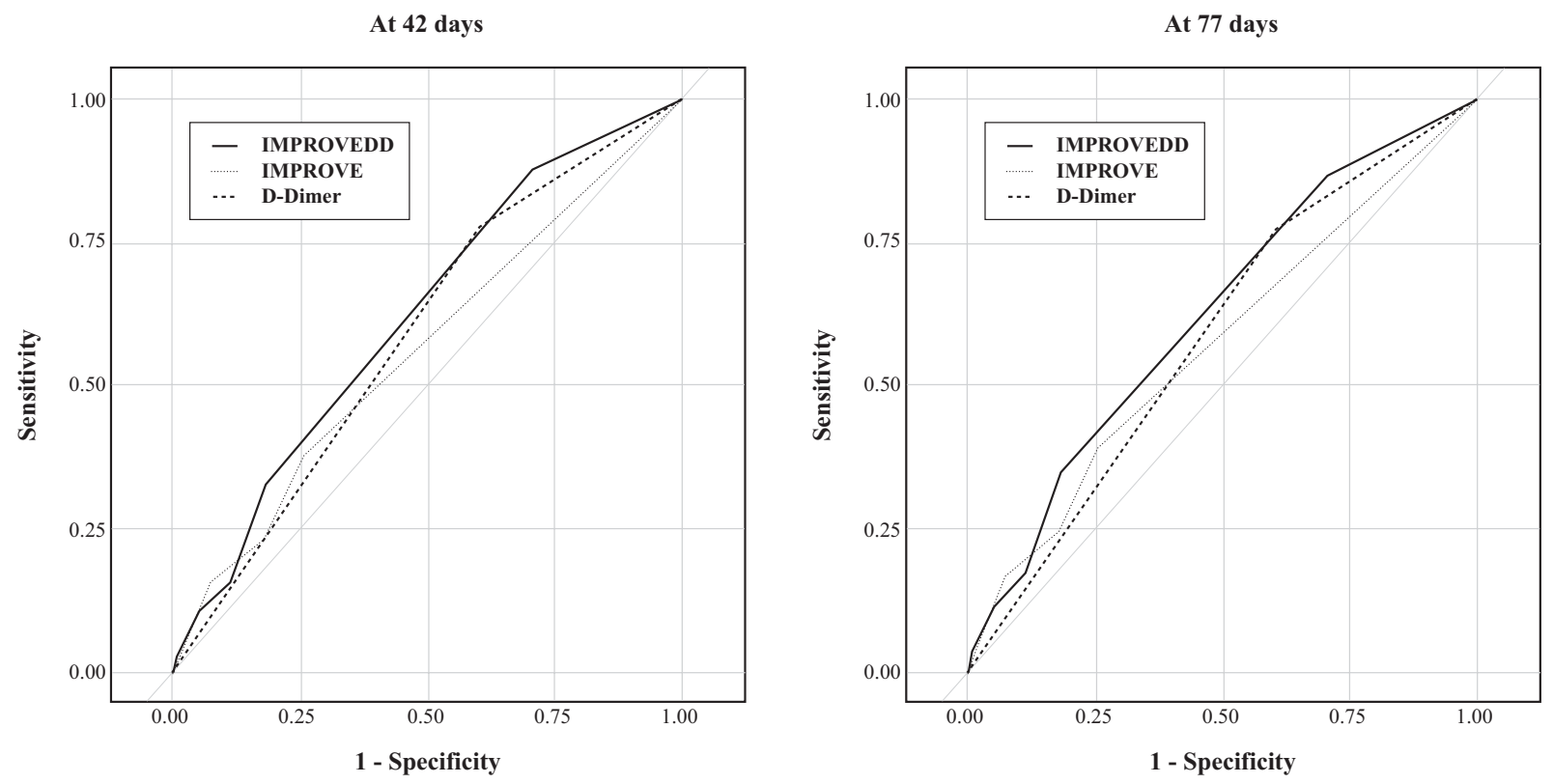

Likelihood Ratio Test Statistics

\begin{tabular}{|l|l|c|c|}
\hline Model & \multicolumn{1}{|c|}{ Comparison } & Chi-Square & P-value \\
\hline At 42 days & $\geq 2 \times$ ULN vs. $<2 \times$ ULN & 11.36 & 0.0008 \\
\hline D-dimer & Per point increase & 4.36 & 0.0366 \\
\hline IMPROVE score & Per point increase & 13.66 & 0.0002 \\
\hline IMPROVEDD score & $\geq 2 \times$ ULN vs. $<2 \times$ ULN & 12.30 & 0.0005 \\
\hline At 77 days & Per point increase & 7.43 & 0.0064 \\
\hline D-dimer & Per point increase & 18.33 & $<0.0001$ \\
\hline IMPROVE score
\end{tabular}

Fig. 2 Receiver-operating-characteristic (ROC) curves for D-dimer, IMPROVE, and IMPROVEDD models in predicting symptomatic VTE.

Table 6 Observed and predicted risk by the IMPROVEDD VTE risk score

\begin{tabular}{|l|l|l|l|l|l|l|l|}
\hline IMPROVEDD score & $\begin{array}{l}\text { Patients, } \\
n(\%)\end{array}$ & \multicolumn{2}{|l|}{ At 42 d } & At 77 d \\
\cline { 3 - 8 } & Event, $\boldsymbol{n}$ & $\begin{array}{l}\text { Observed } \\
\text { risk, \% }\end{array}$ & $\begin{array}{l}\text { Predicted } \\
\text { risk, \% }\end{array}$ & Event, $\boldsymbol{n}$ & $\begin{array}{l}\text { Observed } \\
\text { risk, \% }\end{array}$ & $\begin{array}{l}\text { Predicted } \\
\text { risk, \% }\end{array}$ \\
\hline 0 & $48(0.7)$ & 0 & 0.0 & 0.4 & 0 & 0.0 & 0.5 \\
\hline 1 & $2,053(28.4)$ & 10 & 0.5 & 0.6 & 13 & 0.6 & 0.7 \\
\hline 2 & $279(3.9)$ & 3 & 1.1 & 0.8 & 3 & 1.1 & 1.0 \\
\hline 3 & $3,520(48.7)$ & 42 & 1.2 & 1.2 & 47 & 1.3 & 1.4 \\
\hline 4 & $510(7.0)$ & 14 & 2.7 & 1.6 & 17 & 3.3 & 1.9 \\
\hline$\geq 5$ & $825(11.4)$ & 13 & 1.6 & 2.2 & 17 & 2.1 & 2.7 \\
\hline
\end{tabular}

the incorporation of biomarker may enhance the performance of clinical RAM, it remains uncertain whether this refinement is clinically meaningful to warrant the additional complexity and expense. Future studies are therefore required to evaluate the practicability of IMPROVEDD score in the "real-world" setting.

\section{Limitations}

VTE risk factors encompassed in the analyses were not all inclusive. First, other previously described risk factors (e.g., myocardial infarction, chronic obstructive pulmonary disease, chronic kidney disease, and dyslipidemia) and 
Table 7 Risk stratification by the IMPROVEDD VTE risk category

\begin{tabular}{|c|c|c|c|}
\hline Risk category & Event rate $(95 \% \mathrm{Cl})$ & Odds ratio $(95 \% \mathrm{Cl})$ & $p$-Value \\
\hline \multicolumn{4}{|l|}{ At $42 \mathrm{~d}$} \\
\hline At-risk ( $\geq 2$ points) & $1.40 \%(1.08-1.72 \%)$ & $2.97(1.53-5.77)$ & 0.0002 \\
\hline Low-risk (0-1 points) & $0.48 \%(0.18-0.77 \%)$ & Reference & \\
\hline \multicolumn{4}{|l|}{ At $77 \mathrm{~d}$} \\
\hline At-risk ( $\geq 2$ points) & $1.64 \%(1.29-1.98 \%)$ & $2.67(1.49-4.80)$ & 0.0002 \\
\hline Low-risk (0-1 points) & $0.62 \%(0.28-0.95 \%)$ & Reference & \\
\hline
\end{tabular}

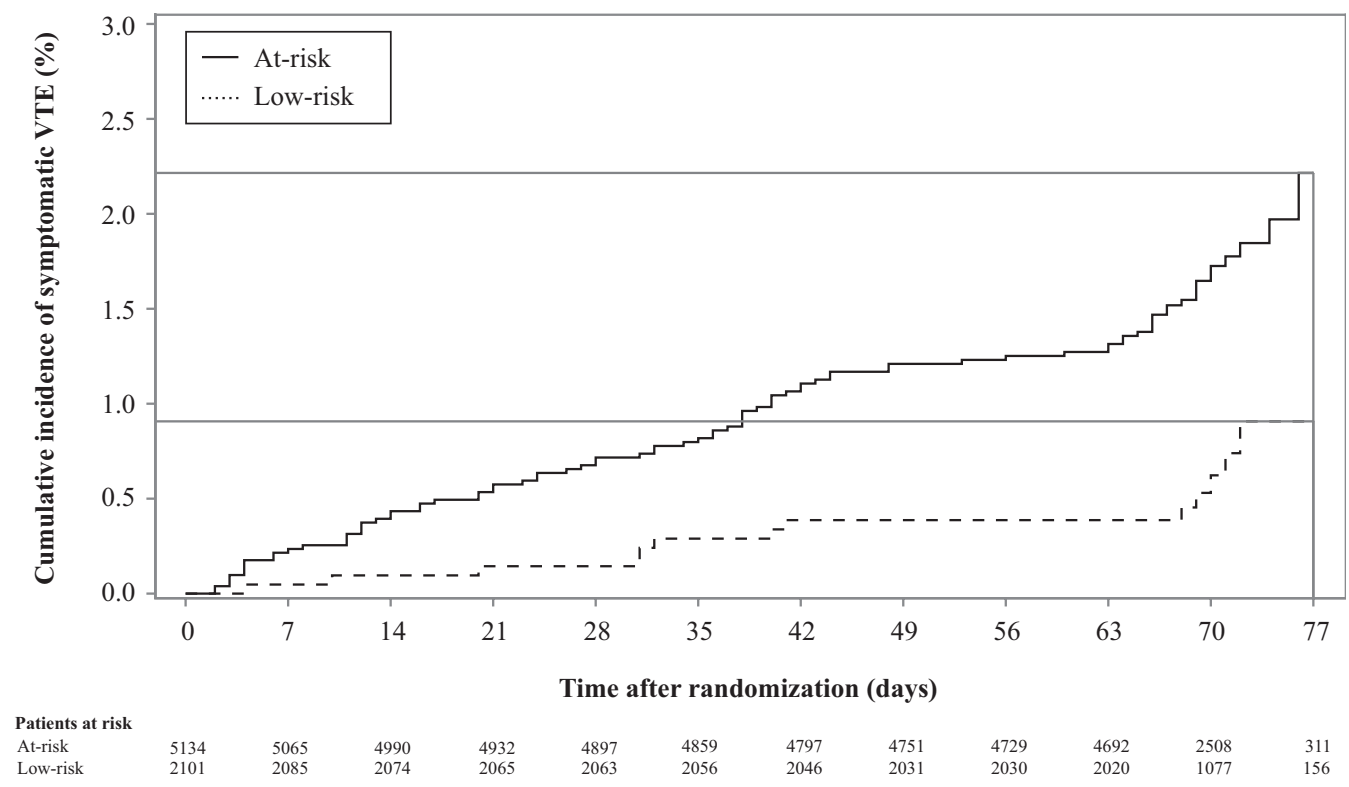

Fig. 3 Kaplan-Meier curves for symptomatic VTE stratified by the IMPROVEDD risk category.

biomarkers (e.g., prothrombin fragment $1+2$, soluble Pselectin, clotting factor VIII, and thrombin generation potential) may offer additional refinement in risk stratification among acutely ill, hospitalized medical patients. Second, small numbers of events in certain score categories may preclude an accurate calibration of the IMPROVEDD model. Also the lack of patients who were immobilized $\geq 7$ days as a risk factor in the IMPROVE model may have altered the model characteristics. Nonetheless, the cutoff of an IMPROVEDD score of $\geq 2$ demonstrated excellent discriminatory capacity in this population. Third, asymptomatic DVT was not included as a component of the outcome in the analysis. Fourth, it should be noted that D-dimer measurement could be influenced by the analytical methods and reporting standards from different laboratories. ${ }^{25}$ Finally, the data were derived from a population that agreed to participate in a clinical trial. The results are applicable to patients who received primary prophylaxis with either standard-duration enoxaparin or extended-duration betrixaban and may not be generalizable to other settings.

\section{Conclusion}

Baseline D-dimer level demonstrated a robust, incremental prognostic value to the IMPROVE RAM in VTE risk stratification for medical patients. Strategies to improve VTE risk stratification should consider incorporation of D-dimer measurement into standard RAMs. An IMPROVEDD VTE risk score of two or greater identifies a subset of hospitalized, medically ill patients receiving thromboprophylaxis at a sustained, heightened risk for symptomatic VTE through 77 days. This population may potentially benefit from an extended course of thromboprophylaxis. Independent validation and impact analysis should be undertaken before employing the IMPROVEDD VTE risk score in clinical practice.

\section{Clinical Trial Registration}

URL: http://www.clinicaltrials.gov. Unique identifier: NCT01583218. 


\section{Conflict of Interest \\ None declared.}

Funding

The study was funded by Portola Pharmaceuticals, Inc.

\section{References}

1 Jha AK, Larizgoitia I, Audera-Lopez C, Prasopa-Plaizier N, Waters H, Bates DW. The global burden of unsafe medical care: analytic modelling of observational studies. BMJ Qual Saf 2013;22(10):809-815

2 Kahn SR, Lim W, Dunn AS, et al. Prevention of VTE in nonsurgical patients: Antithrombotic Therapy and Prevention of Thrombosis, 9th ed: American College of Chest Physicians Evidence-Based Clinical Practice Guidelines. Chest 2012;141(2, Suppl):e195S-e226S

3 Qaseem A, Chou R, Humphrey LL, Starkey M, Shekelle P; Clinical Guidelines Committee of the American College of Physicians. Venous thromboembolism prophylaxis in hospitalized patients: a clinical practice guideline from the American College of Physicians. Ann Intern Med 2011;155(09):625-632

4 ISTH Steering Committee for World Thrombosis Day. Venous thromboembolism: A Call for risk assessment in all hospitalised patients. Thromb Haemost 2016;116(05):777-779

5 Flanders SA, Greene MT, Grant P, et al. Hospital performance for pharmacologic venous thromboembolism prophylaxis and rate of venous thromboembolism: a cohort study. JAMA Intern Med 2014;174(10):1577-1584

6 Greene MT, Spyropoulos AC, Chopra V, et al. Validation of risk assessment models of venous thromboembolism in hospitalized medical patients. Am J Med 2016;129(09):1001.e9-1001.e18

7 Desjardins L, Bara L, Boutitie F, et al. Correlation of plasma coagulation parameters with thromboprophylaxis, patient characteristics, and outcome in the MEDENOX study. Arch Pathol Lab Med 2004;128(05):519-526

8 Fan J, Li X, Cheng Y, Yao C, Zhong N; Investigators Group. Measurement of D-dimer as aid in risk evaluation of VTE in elderly patients hospitalized for acute illness: a prospective, multicenter study in China. Clin Invest Med 2011;34(02):E96-E104

9 Cohen AT, Harrington R, Goldhaber SZ, et al. The design and rationale for the Acute Medically Ill Venous Thromboembolism Prevention with Extended Duration Betrixaban (APEX) study. Am Heart J 2014;167(03):335-341

10 Mahan CE, Liu Y, Turpie AG, et al. External validation of a risk assessment model for venous thromboembolism in the hospitalised acutely-ill medical patient (VTE-VALOURR). Thromb Haemost 2014;112(04):692-699

11 Rosenberg D, Eichorn A, Alarcon M, McCullagh L, McGinn T, Spyropoulos AC. External validation of the risk assessment model of the International Medical Prevention Registry on Venous
Thromboembolism (IMPROVE) for medical patients in a tertiary health system. J Am Heart Assoc 2014;3(06):e001152

12 Spyropoulos AC, Anderson FA Jr, FitzGerald G, et al; IMPROVE Investigators. Predictive and associative models to identify hospitalized medical patients at risk for VTE. Chest 2011;140(03): 706-714

13 Cohen AT, Harrington RA, Goldhaber SZ, et al; APEX Investigators. Extended thromboprophylaxis with betrixaban in acutely ill medical patients. N Engl J Med 2016;375(06):534-544

14 Pencina MJ, D'Agostino RB Sr, D’Agostino RB Jr, Vasan RS. Evaluating the added predictive ability of a new marker: from area under the ROC curve to reclassification and beyond. Stat Med 2008; 27(02):157-172, discussion 207-212

15 Vickers AJ, Elkin EB. Decision curve analysis: a novel method for evaluating prediction models. Med Decis Making 2006;26(06): 565-574

16 Lester W, Freemantle N, Begaj I, Ray D, Wood J, Pagano D. Fatal venous thromboembolism associated with hospital admission: a cohort study to assess the impact of a national risk assessment target. Heart 2013;99(23):1734-1739

17 Roberts LN, Porter G, Barker RD, et al. Comprehensive VTE prevention program incorporating mandatory risk assessment reduces the incidence of hospital-associated thrombosis. Chest 2013;144(04):1276-1281

18 Catterick D, Hunt BJ. Impact of the national venous thromboembolism risk assessment tool in secondary care in England: retrospective population-based database study. Blood Coagul Fibrinolysis 2014;25(06):571-576

19 Barbar S, Noventa F, Rossetto V, et al. A risk assessment model for the identification of hospitalized medical patients at risk for venous thromboembolism: the Padua Prediction Score. J Thromb Haemost 2010;8(11):2450-2457

20 Kucher N, Koo S, Quiroz R, et al. Electronic alerts to prevent venous thromboembolism among hospitalized patients. N Engl J Med 2005;352(10):969-977

21 Woller SC, Stevens SM, Jones JP, et al. Derivation and validation of a simple model to identify venous thromboembolism risk in medical patients. Am J Med 2011;124(10):947-954.e2

22 Pabinger I, Thaler J, Ay C. Biomarkers for prediction of venous thromboembolism in cancer. Blood 2013;122(12):2011-2018

23 Eichinger S, Heinze G, Jandeck LM, Kyrle PA. Risk assessment of recurrence in patients with unprovoked deep vein thrombosis or pulmonary embolism: the Vienna prediction model. Circulation 2010;121(14):1630-1636

24 Raskob GE, Spyropoulos AC, Zrubek J, et al. The MARINER trial of rivaroxaban after hospital discharge for medical patients at high risk of VTE. Design, rationale, and clinical implications. Thromb Haemost 2016;115(06):1240-1248

25 Lippi G, Tripodi A, Simundic AM, Favaloro EJ. International survey on D-dimer test reporting: a call for standardization. Semin Thromb Hemost 2015;41(03):287-293 